\title{
Kronika Katedry Nauk Historyczno-Prawnych i Komparatystyki Prawniczej (rok 2013)
}

\section{Nowa nazwa i struktura Katedry}

W 2013 roku Rada Wydziału Prawa UwB podjęła uchwałę o przekształceniu Katedry Nauk Historyczno-Prawnych w Katedrę Nauk Historyczno-Prawnych i Komparatystyki Prawniczej. Kierownikiem nowo utworzonej Katedry został dr Adam Czarnota, prof. UwB. Zmianie uległa także struktura wewnętrzna Katedry, w ramach której w niezmienionej postaci pozostał jedynie Zakład Historii Państwa i Prawa (kierownik dr hab. Jarosław Wołkonowski, prof. UwB). Powołano do życia nowy Zakład Historii Idei Społecznych, Politycznych i Prawnych (kierownik dr Adam Czarnota, prof. UwB). W miejsce Zakładu Prawa Rzymskiego i Kanonicznego utworzono dwa Zakłady: Prawa Rzymskiego (kierownik dr hab. Piotr Niczyporuk, prof. UwB) oraz Łacińskiej Kultury Prawnej (kierownik ks. dr hab. Florian Lempa, prof. UwB).

\section{Publikacje}

\section{Monografie}

Prawnicy Katedry byli autorami trzech monografii, które ukazały się nakładem wydawnictwa Temida 2. Dwie spośród tych monografii - Kanoniczna ochrona karna przed nadużyciami seksulanymi oraz Kompetencje, uprawnienia i obowiazki w Kościele katolickim napisał Florian Lempa. Natomiast Piotr Niczyporuk wydał książkę Bankierzy i operacje bankierskie w starożytnym Rzymie. Ponadto, Adam Czarnota był współautorem książki The Anxiety of the Jurist. Legality, Exchange and Judgement (red. Max del Mar i Caludio Michelon, Ashgate, Farnham-Burlington), w której zamieścił rozdział History in the service of live: law's authority and dealing with the past.

\section{Artykuły}

Pracownicy Katedry są autorami kilkunastu artykułów, które zostały opublikowane na łamach zagranicznych i krajowych periodyków naukowych, wydawnictw pokonferencyjnych oraz ksiąg pamiątkowych. Artykuł Adama Czarnoty $\mathrm{w}$ języku hiszpańskim pt. El estado derecho post-comunista en una Union Europea post-democratica. Reflexiones escépticas de un jurista la unidad europea uka- 
zał się w czasopiśmie „Puente@Europa” (2013, nr 4), natomiast w ukraińskim periodyku „Filosofia prawa” (2013, nr 2) autor ten zamieścił artykuł On transitional Justice. Na łamach wydawanego w Serbii periodyku „Pravni život” (2013, nr 12) Piotr Fiedorczyk opublikował artykuł Polish Family Law and Family Life Before the European Court of Human Rights.

Spośród publikacji krajowych na uwagę zasługują opublikowane w „Czasopiśmie Prawno-Historycznym" artykuły Adama Czarnoty (Republikańska koncepcja rządów prawa czyli co historyk idei może dać filozofowi?, CPH 2013, t. LXV, z. 2) oraz Piotra Fiedorczyka (O prawie i doktrynach politycznoprawnych Zwiazku Radzieckiego. Uwagi w zwiazku z ponownymi wydaniami książek A. Lityńskiego $i$ A. Bosiackiego, CPH, t. LXV, z. 1). Ponadto Adam Czarnota zamieścił w czasopiśmie „Prawo i Więź" następujące artykuły:

- Kryzys nauki prawa a edukacja prawnicza. O niekonieczności produkowania „użytecznych idiotów" (PiW 2013, nr 2);

- Republikańska idea rzadów prawa, czyli dlaczego filozof prawa potrzebuje wiedzy historycznej? (PiW 2013, nr 4).

W „Przeglądzie Prawa Wyznaniowego” (2013, t. 5) ukazał się artykuł Marcina Łysko Przepisy wyznaniowe w konstytucjach II Rzeczypospolitej. Na łamach „Studia Iuridica Lublinensia” (2013, t. XIX) Piotr Fiedorczyk opublikował artykuł Debata nad uchwaleniem polsko-czechostowackiego prawa rodzinnego w czechosłowackim Zgromadzeniu Narodowym w 1949 r. Z kolei artykuł Floriana Lempy Problematyka pokoju w pogladach Marii Szyszkowskiej został opublikowany w czasopiśmie „Studia Społeczne” (2013, nr 1). Ponadto w „Białostockich Studiach Prawniczych" (2013, nr 13) Piotr Niczyporuk zamieścił recenzję książki Marii Pia Baccari Vari, Curator ventris. Il conceptio, la donna e la respublica. Tra storia e attualità, Torino 2012.

W pracach zbiorowych ukazały się artykuły następujących pracowników Katedry:

- Piotra Fiedorczyka - Administracyjna regulacja działalności gospodarczej, [w:] Synteza prawa polskiego 1918-1939, red. T. Guz, J. Głuchowski, M. R. Pałubska, Warszawa 2013;

- Karola Kuźmicza - Istota utopii komunizujacych, [w:] Oblicza utopii, obłudy i zakłamania, red. W. Łysiak, Poznań 2013, oraz Nieutopijny sens kooperatyzmu, [w:] Dzisiejsze znaczenie ideałów spółdzielczości, red. M. Szyszkowska, Warszawa 2013;

- Floriana Lempy - Kary kościelne a zawarcie zwiazku małżeńskiego, [w:] Rodzina w prawie. Ksiegga pamiątkowa dedykowana ks. prof. dr. hab. Ryszardowi Sztychmilerowi z okazji 65. rocznicy urodzin i 30-lecia pracy naukowej, red. M. Różański, J. Krzywkowska, Olsztyn 2013;

- Marcina Łysko - Środki zaskarżania orzeczeń karno-administracyjnych w Polsce Ludowej, [w:] Szczególne środki zaskarżenia w ujęciu komparatystycznym, red. D. Gil, Stalowa Wola 2013; Socjalistyczna reforma orzecznictwa karno- 
-administracyjnego Polski Ludowej, [w:] Pro memoriał. Księga pamiatkowa dla uczczenia pamięci Profesor Krystyny Kamińskiej, red. A. Gaca, Torun 2013, oraz Aparat biurokratyczny orzecznictwa karno-administracyjnego Polski Ludowej, [w:] Z dziejów biurokracji t. V, cz. II, red. A. Gaca, A. Górak, Z. Naworski, Lublin - Toruń - Włocławek 2013. Artykuł ten ukazał się także w wersji elektronicznej (na stronie www.komunizm.net.pl) w czasopiśmie: „Komunizm: System - Ludzie - Dokumentacja" 2013, t. II;

- Piotra Niczyporuka - Operacje wykonywane przez bankierów rzymskich (argentarii), [w:] Krytyka prawa. Niezależne studia nad prawem, t. 5: Przedsiębiorczość. Aspekty prawne, Warszawa 2013;

- Jarosława Wołkonowskiego - Bilans kapitału ludzkiego Litwy w kontekście konkurencyjności gospodarki, [w:] Wplyw globalizacji i integracji na konkurencyjność nowych krajów czlonkowskich Unii Europejskiej, red. A. Grynia, Wilno 2013, oraz Polska i Litwa na tle standardów międzynarodowej ochrony mniejszości narodowych $i$ etnicznych $w$ Polsce, [w:] Sąsiedztwo i pogranicze - między konfliktem a wspótpraca, red. R. Łoś, J. Reginia-Zacharski, Łódź 2013.

\section{Konferencje naukowe}

\section{Zagraniczne}

Spośród pracowników Katedry w zagranicznych konferencjach naukowych uczestniczyli: Adam Czarnota, Piotr Fiedorczyk, Marcin Łysko oraz Piotr Niczyporuk.

Największą aktywnością wykazał się Adam Czarnota, który brał udział w:

- zorganizowanej przez European Consortium for Political Research w Mainz (Niemcy) w dniach 11-16 marca 2013 r. konferencji "Joint Meeting European Consortium for Political Research". Wystąpił z referatem Transitional Justice as a constitutional process. Towards integration of transitional justice and society theory;

- zorganizowanej przez Uniwersytet w Czerniowcach (Ukraina) w dniach 17-21 kwietnia 2013 r. konferencji „Eugen Ehrlich and his legacy”. Wygłosił referat Eugen Ehrlich in XXI century global Bukovina;

- zorganizowanym wspólnie przez Uniwersytet w Rio de Janeiro i Uniwersytet w Porto Allegro Światowym Kongresie Filozofii Prawa (20 lipca 4 sierpnia 2013 r.). Wygłosił referat Rule of law and transitional Justice;

- zorganizowanej przez Uniwersytet w Sydney (16-18 sierpnia 2013 r.) konferencji Australian Legal Philosophy Conference, podczas której wystąpił z referatem Theory of rule of law and challenge of transition justice;

- zorganizowanej w dniach 2-6 września 2013 r. przez RCSL i Science Politique w Tuluzie (Francja) konferencji "Sociology of law and political action", 
$\mathrm{w}$ trakcie której wygłosił referat XX years of the International Institute for Sociology and Law;

- konferencji „Utopía, Historia y Epistemología en la Construcción de Europa y América Latina" (Buenos Aires, 16-22 listopada 2013 r.) Wygłosił referat La "construcción" de Europa a lo largo del siglo XX: modelos nazistas, comunistas e integracionistas.

Ponadto podczas pobytu $\mathrm{w}$ SUN Institute $\mathrm{w}$ Birmie $\mathrm{w}$ dniach 1-12 maja 2013 r. wygłosił wykład Constitutionalism, constitutional justice and national reconciliation.

Podczas pobytu w Nowym Jorku w czerwcu 2013 r. Piotr Fiedorczyk uczestniczył w dwóch konferencjach naukowych. Pierwsza z nich - ISFL Regional Conference - została zorganizowana przez Brooklyn Law School w dniach 6-8 czerwca. Z kolei podczas odbywającej się w Benjamin Cardozo School of Law na Yeshiva University w dniach 10-11 czerwca konferencji „The Jurisprudence of Family Relations: Privacy, Autonomy and Whether States Should Regulate Family Relations" wygłosił referat oraz przewodniczył obradom. Piotr Fiedorczyk brał także udział w 26. edycji konferencji "Skola prirodnogo prava” w Górze Kopaonik (Serbia, 13-17 grudnia 2013 r.), gdzie wygłosił referat Polish Family Law and Family Life before the European Court of Human Rights. Ponadto uczestniczył w konferencji „Public and Private Justice Course. Dispute Resolutions in Modern Societies", która miała miejsce w Dubrowniku w dniach 27-29 maja $2013 \mathrm{r}$.

Marcin Łysko uczestniczył w zorganizowanym wspólnie przez Uniwersytety w Lille i Ghent w dniach 13-17 maja 2013 r. XIX ${ }^{\text {th }}$ Annual Forum of Young Legal Historians. Wygłosił referat The legal situation of women in the 2nd Republic of Poland. Piotr Niczyporuk brał udział w międzynarodowej konferencji "Аревние и современные дороги коммерции: философия, экономика, право. Родос, Рим и их наследие", która odbyła się w Suzdalu w dniach 3-6 października 2013 r. Wystąpił z referatem Римские банкиры (argentarii) u ux операции oraz przewodniczył obradom plenarnym.

\section{Pozostałe wyjazdy zagraniczne}

W dniach 29 października - 5 listopada 2013 r. Piotr Niczyporuk odbył kwerendę naukową na Uniwersytecie Sorbona (Paris I). Krzysztof Szczygielski w dniach 17-24 września 2013 r. odbył staż w ramach Lifelong Learning Programme - Erasmus Staff Mobility for Training (STT) na Università degli Studi di Bari (Włochy). Szkolenie poświęcone było prawnym, kulturowym i religijnym aspektom funkcjonowania rodziny w starożytnym Rzymie. 


\section{Krajowe}

Pracownicy Katedry uczestniczyli w XI Zjeździe Katedr Doktryn Polityczno-Prawnych „Wolność w doktrynach społecznych, politycznych i prawnych", który miał miejsce w Uniejowie w dniach 18-20 września 2013 r. W roli referentów wystąpili Adam Czarnota (referat J. S. Milla konocecja wolnosci. Uwagi z perspektywy XXI wieku) i Karol Kuźmicz (referat Utopie a wolność jednostki. Mit czy postulat?).

W Ogólnopolskim Sympozjum Romanistów „Rzymskie wzory współczesnych rozwiązań prawnych" (Sucha Beskidzka, 1-4 maja 2013 r.) uczestniczyli Piotr Niczyporuk (referat Korzenie 'cura ventris' w prawie polskim) oraz Krzysztof Szczygielski (wystąpienie Inventio thesauri: tradycje prawa rzymskiego we wspótczesnych regulacjach europejskich). Podczas IV Kazimierskiego Seminarium z prawa rzymskiego „Prawo w poezji, poezja w prawie. Refleksje antyczne” (Kazimierz Dolny, 17-19 maja 2013 r.) referaty wygłosili:

- Piotr Kołodko - Obraz kwestury w wybranych źródłach literackich;

- Piotr Niczyporuk - Bankierzy rzymscy u Liwiusza;

- Krzysztof Szczygielski - Prawo w poezji, poezja w prawie. Refleksje antyczne. Uczestnicząc w II Ogólnopolskim Sympozjum Historyków Prawa (Katowice, 19 września 2013 r.), referaty wygłosili:

- Piotr Fiedorczyk - Ewolucja prawa rodzinnego w Polsce Ludowej;

- Marcin Łysko - Ewolucja systemu kar w prawie wykroczeń Polski Ludowej;

- Mariusz Mohyluk - Ewolucja radzieckiego ustawodawstwa cywilnego w pogladach prawników II Rzeczypospolitej.

W zorganizowanej na Wydziale Prawa UwB przez funkcjonujący w ramach Katedry Zakład Łacińskiej Kultury Prawnej Ogólnopolskiej Konferencji Naukowej „Związki pozamałżeńskie na przestrzeni wieków” (Białystok, 22-23 października 2013 r.) uczestniczyli:

- Piotr Fiedorczyk - referat: Status dzieci pozamalżeńskich w prawie rodzinnym Polski Ludowej;

- Karol Kuźmicz z referatem Filozofowie na temat matżeństwa, rodziny, seksu i wychowania;

- Krzysztof Szczygielski - wystąpienie: Publiczny lub notoryczny konkubinat jako źródło małżeńskiej przeszkody przyzwoitości publicznej w prawie kanonicznym.

Podczas Ogólnopolskiej Konferencji Naukowej „Prawo i literatura”, która także miała miejsce na Wydziale Prawa UwB 6 grudnia 2013 r., z referatami wystąpili:

- Filip Cyuńczyk - Wydział Prawa Uniwersytetu w Dorpacie we wspomnieniach absolwentów;

- Ireneusz Grat - Kultura jako wytwór stosunków ekonomicznych $i$ społecznych. O partyjności w literaturze słów kilka; 
- Piotr Fiedorczyk - Prawo i prawnicy we wspomnieniach Stefana Grzybowskiego;

- Piotr Kołodko - Słowackiego Juliusza o prawie rozważania. Kilka uwag na marginesie Samuela Zborowskiego;

- Karol Kuźmicz - Prawo i utopie na przykładzie „Kodeksu natury” Étiena-Gabriela Morelly;

- Marcin Łysko - Problem chuligaństwa w Polsce Ludowej na przykładzie powieści Leopolda Tyrmanda "Zly";

- Piotr Niczyporuk - Bankierzy w "Żywotach cezarów” Swetoniusza;

- Krzysztof Szczygielski - Prawo rzymskie w wykładach "Literatury słowiańskiej" Adama Mickiewicza.

Adam Czarnota uczestniczył w zorganizowanej przez UJ konferencji „Neutralizacja aksjologiczna prawa" (Hebdów, 24-27 stycznia 2013 r.), wygłaszając referat Dylematy neutralizacji przez prawo. Brał także udział w poświęconym problematyce tolerancji religijnej IX Opolskim Colloquium Prawno-Historycznym (Brzeg Opolski, 15-16 maja 2013 r.), podczas którego wystąpił z referatem Protestantyzm, republikanizm i idea tolerancji religijnej. Karol Kuźmicz uczestniczył w zorganizowanej w Nałęczowie (3-5 czerwca 2013 r.) Międzynarodowej Konferencji Naukowej „Demokracja w XXI wieku z perspektywy jednostki deklarowane wartości a rzeczywistość". Wygłosił referat Demokracja jako utopia społeczno-polityczna. Ponadto, podczas odbywającej się w Białymstoku konferencji naukowej „Literatura w granicach prawa (XIX-XX w.)” wystąpił z referatem O podłożach najstynniejszych sporów między filozofami i uczonymi a władzą. Marcin Łysko uczestniczył w konferencji naukowej „Szczególne środki zaskarżenia w ujęciu komparatystycznym" (Stalowa Wola, 11 marca 2013 r.), wygłaszając referat Środki zaskarżania orzeczeń karno-administracyjnych w Polsce Ludowej. Podczas Międzynarodowej Konferencji Naukowej „Diritti fondamentali. Etica e diritto" (Warszawa, 11 czerwca 2013 r.) z referatem Il diritto a vedere il figlio nel sistema giuridico polacco wystąpił Krzysztof Szczygielski. Piotr Kołodko oraz Piotr Niczyporuk uczestniczyli w organizowanych przez UW Ogólnopolskich spotkaniach romanistów (Warszawa, 26 marca, 9 kwietnia, 12 czerwca 2013 r.).

\section{Członkostwo w komitetach redakcyjnych czasopism naukowych}

Pracownicy Katedry weszli w skład komitetów redakcyjnych zagranicznych i krajowych czasopism naukowych. Adam Czarnota pełnił funkcję redaktora naczelnego wydawanego przez Międzynarodowy Instytut Socjologii Prawa w Onati (Hiszpania) periodyku "Onati Socio-Legal Series". Jest członkiem rady naukowej wydawanego we Włoszech pisma "European Legal Roots", a także „Brasilian Socio-Legal Studies Journal”. Przewodniczy radzie naukowej Krytyki Prawa i jest członkiem rad naukowych czasopism "Silesian Legal Studies Journal” oraz „Ruch Prawniczy, Ekonomiczny, Socjologiczny”. Piotr Niczyporuk został członkiem kolegium redakcyjnego uznanego międzynaro- 
dowego czasopisma romanistycznego „Ius Antiqum”. Adam Czarnota pełnił funkcję zastępcy redaktora naczelnego czasopisma "Prawo i Więz”. Piotr Niczyporuk wspólnie z Piotrem Kołodko redagowali wydawane przez Wydział Prawa UwB w języku angielskim czasopismo „Studies in Logic, Grammar and Rhetoric". Ponadto Piotr Niczyporuk pełnił funkcję redaktora XIII tomu „Białostockich Studiów Prawniczych", w pracach nad którym uczestniczyli jako współredaktorzy Piotr Kołodko oraz Karol Kuźmicz.

\section{Obrona Katarzyny Kręźlewicz}

W dniu 2 września 2013 r. odbyła się publiczna obrona rozprawy doktorskiej mgr Katarzyny Kręźlewicz Lex Cornelia de falsis - ustawa Korneliusza Sulli przeciwko fałszerzom z 81 r. p.n.e. Praca została napisana pod kierunkiem dra hab. Piotra Niczyporuka. Recenzentami w przewodzie doktorskim byli prof. dr hab. Jan Zabłocki oraz dr hab. Zuzanna Benincasa. Na mocy uchwały Rady Wydziału Prawa UwB z 17 września 2013 r. Katarzyna Kręźlewicz uzyskała tytuł doktora nauk prawnych, a przebieg jej obrony został oceniony jako wyróżniający.

\section{Nowi doktoranci w Katedrze}

W roku 2013 do grona pracowników Katedry dołączyli jako doktoranci następujący absolwenci Wydziału Prawa UwB:

- Filip Cyuńczyk (promotor Adam Czarnota),

- Przemysław Kowalski (promotor Piotr Niczyporuk),

- Kamil Niewiński (promotor Piotr Niczyporuk),

- Anna Pałka (promotor Piotr Niczyporuk). 